METALLURGY AND FOUNDRY ENGINEERING - Vol. 38, 2012, No. 2

http://dx.doi.org/10.7494/mafe.2012.38.2.99

\author{
Mirosław Karbowniczek*, Andrzej Michaliszyn**, \\ Zygmunt Wcisło**, Wojciech Ślęzak***
}

\title{
ANALYSIS OF THE EFFECT OF $\mathrm{CO}_{2}$ BLOW ON THE OXIDATION OF IRON ALLOYS' ELEMENTS
}

\section{INTRODUCTION}

Transfer of carbon and oxygen between a metal or slag phase and the gas phase containing $\mathrm{CO}_{2}$ and $\mathrm{CO}$ is one of the most crucial steelmaking processes. The equilibrium of those processes, as well as recently, the kinetics was the subject of intensive investigations. The efforts to obtain the extremely pure steel without increasing the amount of non-metallic inclusions need the oxidation methods of carbon, silicon, manganese with the help of gaseous reactants with reduced oxidative properties, such as $\mathrm{CO}$ and $\mathrm{CO}_{2}$. Silicon is removing as a first. Removing large amounts of silicon can lead to an excessive increase in the activity of silica in the slag phase. It leads to a reduction in the basicity of slag, what is disadvantageous from the viewpoint of the next process i.e. dephosphorisation.

\section{THEORETICAL BACKGROUND}

Possible reactions that occur in the system: metal $(\mathrm{Fe}-\mathrm{C})-$ slag $\left(\mathrm{CaO}-\mathrm{SiO}_{2}-\mathrm{FeO}\right)-$ gas $\left(\mathrm{CO}_{2}-\mathrm{CO}\right)$ are given below. Analysis of the order and scope of the occurrence of these reactions can be estimated on the basis from the Gibbs free energy data of them. For each reaction:

$$
\Delta G_{T}=\Delta G_{T}^{0}+R T \ln \frac{\Pi_{i_{\text {prod }}}^{n} a_{i}^{v_{i}} \cdot p_{i}^{v_{i}}}{\Pi_{i_{\text {subst }}^{m}}^{m} a_{i}^{v_{i}} \cdot p_{i}^{v_{i}}}
$$

* Ph.D., D.Sc., ** Ph.D., *** M.Sc.: AGH University of Science and Technology, Faculty of Metals Engineering and Industrial Computer Science, Krakow, Poland; e-mail: mkarbow@agh.edu.pl 
where:

$\Delta G_{T}^{0}-$ standard Gibbs enthalpy of reaction ( $\left.T=298 \mathrm{~K}, p=1 \mathrm{~atm}\right)$,

$\Delta G_{T}$ - real Gibbs enthalpy of reaction for given temperature, pressure and chemical activities of reacting components,

$a_{i}$ - the thermodynamic activity of reagent $i$ of solid or gas phase,

$p_{i}-$ partial pressure of gas reagent $i$,

$v_{i}-$ stoichiometric coefficients of chemical reaction,

$m, n-$ number of substrates and products, respectively.

$\Delta G_{T}^{0}$ data as a function of temperature may be found in the thermodynamic tables. They refer to the standard conditions, i.e., for gases it is 1 atm pressure while for condensed matter phase they are pure components (solid or liquid) or the components of the solutions of the chemical activity equal to 1 .

The carbon dissolved in the metal can react with carbon dioxide gas bubbles existing in metal, according to the reaction:

$$
[\mathrm{C}]+\mathrm{CO}_{2(\mathrm{~g})} \rightarrow 2 \mathrm{CO}
$$

The value of the potential, $\Delta G_{T}$, determines course of this reaction:

$$
\Delta G_{T}=139200-127.1 \cdot T+8.314 \cdot T \ln \frac{p_{\mathrm{CO}}^{2}}{a_{[\mathrm{C}]} \cdot p_{\mathrm{CO}_{2}}}[\mathrm{~J}]
$$

Silicon and manganese may react with blown-in $\mathrm{CO}_{2}$ as follows:

$$
\begin{aligned}
& {[\mathrm{Si}]+\mathrm{CO}_{2(\mathrm{~g})} \rightarrow \mathrm{SiO}_{2(\mathrm{~s})}+[\mathrm{C}]} \\
& \Delta G_{T}=-409400+182.2 \cdot T+8.314 \cdot T \ln \frac{a_{[\mathrm{C}]} \cdot a_{\mathrm{SiO}_{2(\mathrm{~s})}}}{a_{[\mathrm{Si}]} \cdot p_{\mathrm{CO}_{2}}}[\mathrm{~J}] \\
& {[\mathrm{Si}]+2 \mathrm{CO}_{2(\mathrm{~g})} \rightarrow \mathrm{SiO}_{2(\mathrm{~s})}+2 \mathrm{CO}}
\end{aligned}
$$

$$
\begin{aligned}
& \Delta G_{T}=-270030+55.18 \cdot T+8.314 \cdot T \ln \frac{a_{\mathrm{SiO}_{2(\mathrm{~s})}} \cdot p_{[\mathrm{CO}]}^{2}}{a_{[\mathrm{Si}]} \cdot p_{\mathrm{CO}_{2}}^{2}}[\mathrm{~J}] \\
& 2[\mathrm{Mn}]+\mathrm{CO}_{2(\mathrm{~g})} \rightarrow 2 \mathrm{MnO}_{(\mathrm{l})}+[\mathrm{C}] \\
& \Delta G_{T}=-304100+169.46 \cdot T+8.314 \cdot T \ln \frac{a_{[\mathrm{C}]} \cdot a_{\mathrm{MnO}_{(\mathrm{l})}}^{2}}{a_{[\mathrm{Mn}]}^{2} \cdot p_{\mathrm{CO}_{2}}}[\mathrm{~J}]
\end{aligned}
$$




$$
\begin{aligned}
& {[\mathrm{Mn}]+\mathrm{CO}_{2(\mathrm{~g})} \rightarrow \mathrm{MnO}_{(\mathrm{l})}+\mathrm{CO}} \\
& \Delta G_{T}=-82350+21.23 \cdot T+8.314 \cdot T \ln \frac{a_{\mathrm{MnO}_{(\mathrm{l})}} \cdot p_{[\mathrm{CO}]}}{a_{[\mathrm{Mn}]} \cdot p_{\mathrm{CO}_{2}}}[\mathrm{~J}]
\end{aligned}
$$

Gibbs energy values for the above reaction at standard conditions and for 1573 and $1773 \mathrm{~K}$ are presented in Table 1.

Table 1. Calculated Gibbs energy values for the above reaction at standard conditions

\begin{tabular}{||c|c|c||}
\hline Reaction & $\Delta G_{1573}^{0}[\mathrm{~kJ}]$ & $\Delta_{1773}^{0}[\mathrm{~kJ}]$ \\
\hline$(2)$ & -60.73 & -86.15 \\
\hline$(3)$ & -122.80 & -86.36 \\
\hline$(4)$ & -183.23 & -172.20 \\
\hline$(5)$ & -37.53 & -3.65 \\
\hline$(6)$ & -48.96 & -44.71 \\
\hline
\end{tabular}

With increasing temperature the reaction (2) there is a faster, while reactions (3)-(6) slower. Reaction (5) at a temperature of $1773 \mathrm{~K}$ practically ceases to occur.

$\mathrm{K}$. Taguchi et al. [1] have investigated decarbonization and desiliconization of a Fe-C-Si(S) melt with $\mathrm{CO}_{2}$ and $\mathrm{O}_{2}$. They believe that at saturation conditions: $a_{\mathrm{SiO}_{2}}=a_{\mathrm{C}}=1$ at the temperature of $1573 \mathrm{~K}$, the silicon should be oxidized firstly, i.e., before the carbon for $\mathrm{Si}$ content above 0.6 mass \%. They experimentally found that at such conditions $\mathrm{Si}$ is only oxidized. For silicon contents between 0.1 mass \% and 0.6 mass \%, a simultaneous oxidation of carbon and silicon occurs. They also determined the kinetics rates for the considered reactions. The rate for desiliconization is of one order higher than the rate for decarbonization. No hampering effect of sulphur presence on the course of those reactions was noted.

In electric arc furnace some consumption of graphite electrode takes place effected by oxidation of the side surface by oxygen of the air as well as by erosion action of the arc on the top of the electrode. When the gas phase contains $\mathrm{CO}_{2}$ to much extent, another reaction might be the one with the electrode graphite:

$$
\mathrm{C}_{\text {graphite (electrode) }}+\mathrm{CO}_{2} \rightarrow 2 \mathrm{CO}
$$

When the electrode carbon reacts with oxygen or carbon di-oxide, the very structure of the electrode surface may be deformed or destroyed, for instance, as a result of various rates 
of reactions of the carbon grains when compared to the reactions of the coal-tar pitch, i.e., the binder. It may cause a slide of the electrode and carbonization of the metal or slag:

$$
\mathrm{C}_{\text {graphite (electrode) }} \rightarrow[\mathrm{C}]
$$

Also some dissociation of $\mathrm{CO}_{2}$ in electric arc is possible:

$$
\mathrm{CO}_{2} \rightarrow \mathrm{C}+\mathrm{O}_{2}
$$

Thus formed carbon could participate in reduction of slag or dissolve in metal. The oxygen coming from decomposition of $\mathrm{CO}_{2}$ might oxidize the metal.

By $\mathrm{CO}_{2}$ blow, as well slag's oxidation may occur:

$$
2(\mathrm{FeO})+\mathrm{CO}_{2} \rightarrow\left(\mathrm{Fe}_{2} \mathrm{O}_{3}\right)+\mathrm{CO}
$$

\section{POSSIBLE APPLICATIONS IN METALLURGICAL PROCESSES}

During the production of carbon steel in the electric arc furnace it is possible to obtain:

- during the heat it is possible to decarburize the metal bath without major iron losses,

- more efficient degassing (denitriding and dehydrogenating) by injecting double volume of gas,

- intensive homogenization of metal bath,

- facilitation of slag foaming,

- decreasing production costs.

By using $\mathrm{CO}_{2}$ recycling in stainless steel making process in the electric arc furnace it is possible to obtain the following metallurgical benefits:

- degassing (denitriding) by injecting a bigger volume of gas,

- better mixing which makes the chemical composition and temperature more homogenous,

- facilitation of slag foaming,

- improvement of metal bath dephosphorization by better temperature gradient control and better mixing.

M. Lv et al. [2] as a results of research on mixed blowing $\mathrm{CO}_{2}$ in converter steelmaking process, found that using $\mathrm{CO}_{2}$ on top and bottom blowing can reduce the amounts of dust, smoke and iron loss, helps to remove nitrogen and phosphorus in molten steel and can reduce oxygen consumption in process.

Figure 1 shows the method of blast furnace top gas recycling. This process is technically efficient if it is accompanied by separation of $\mathrm{CO}_{2}$ from the gas. Gained $\mathrm{CO}_{2}$ can be used in steelmaking processes. Apart from using $\mathrm{CO}_{2}$ recycling technology in the steelmaking process in the electric arc furnaces, there are also other technologies of $\mathrm{CO}_{2}$ used in oxygen converters. Figure 2 shows $\mathrm{CO}_{2}$ recycling technologies in oxygen converters. The obtained effects are similar to those from electric arc furnaces - Figure 3. 


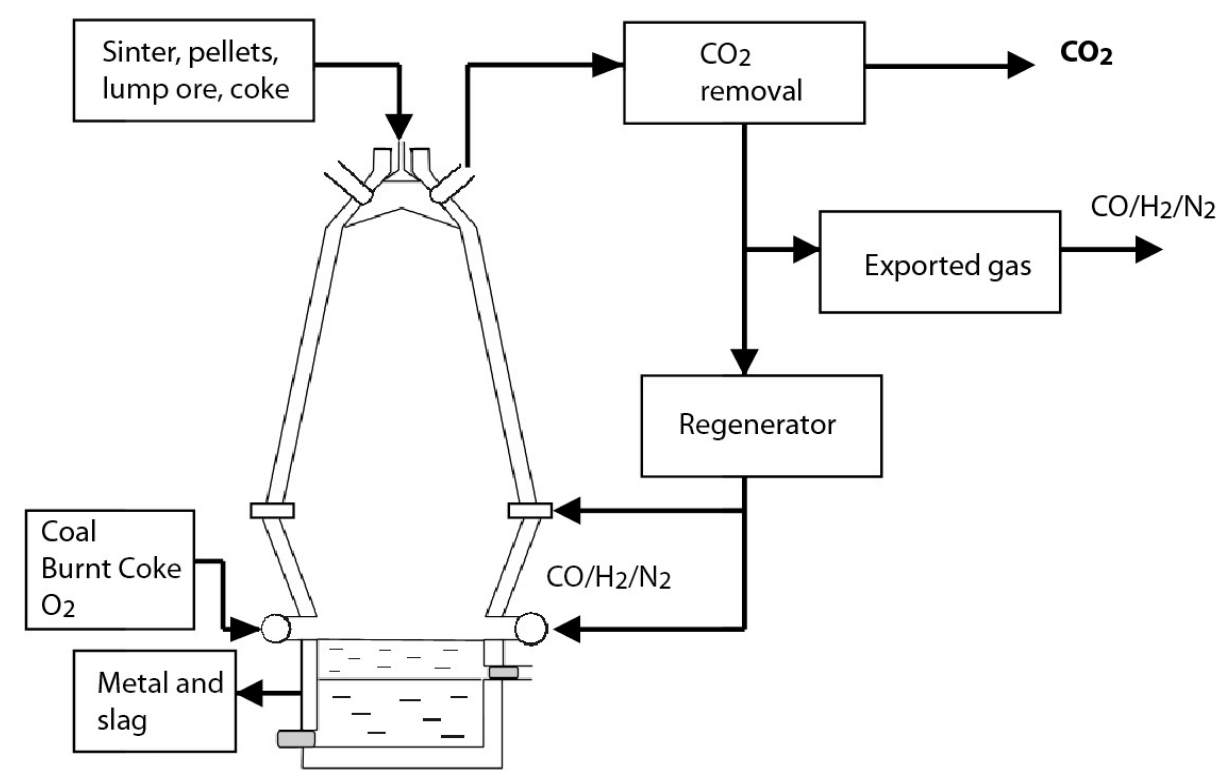

Fig. 1. Blast furnace top gas recycling

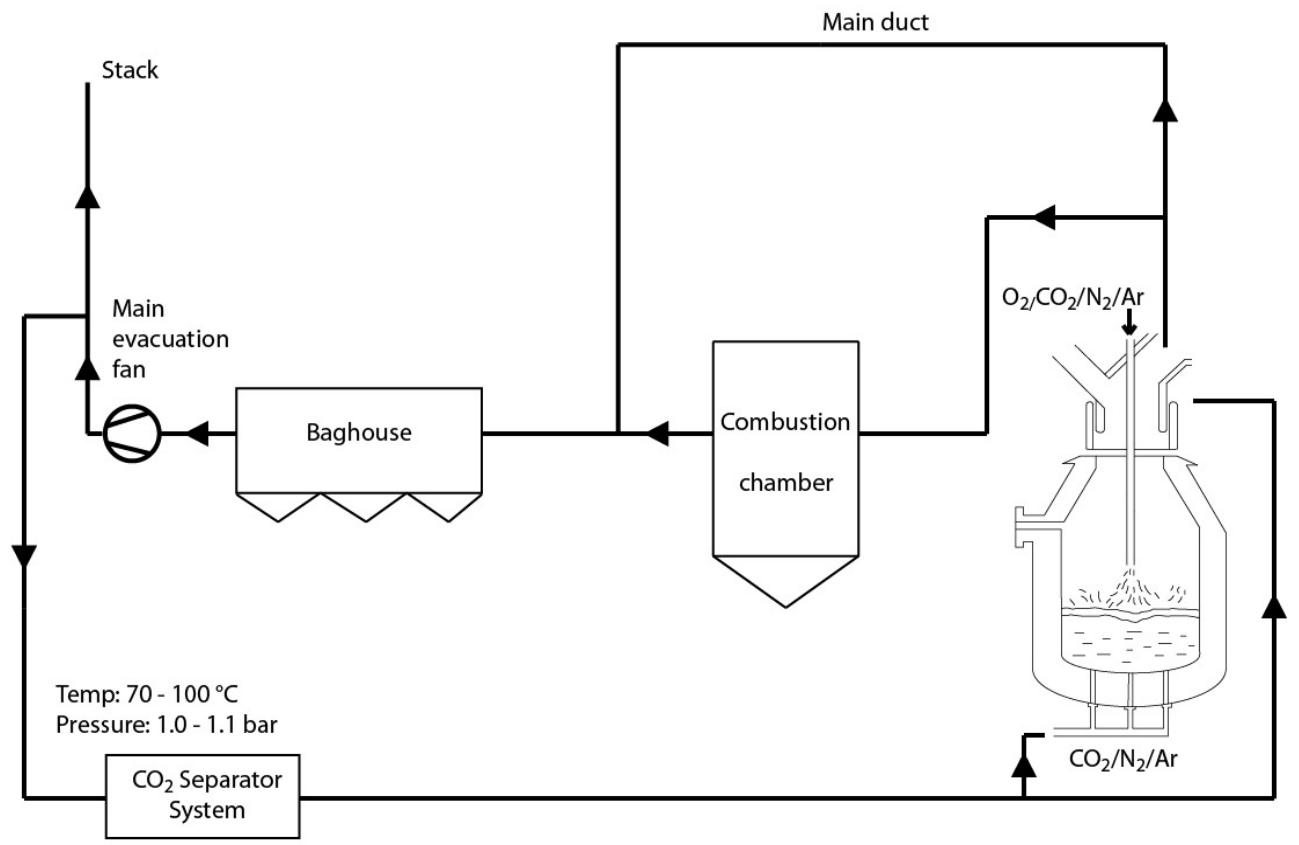

Fig. 2. The use of $\mathrm{CO}_{2}$ in the oxygen converter with a combined blowing technology 


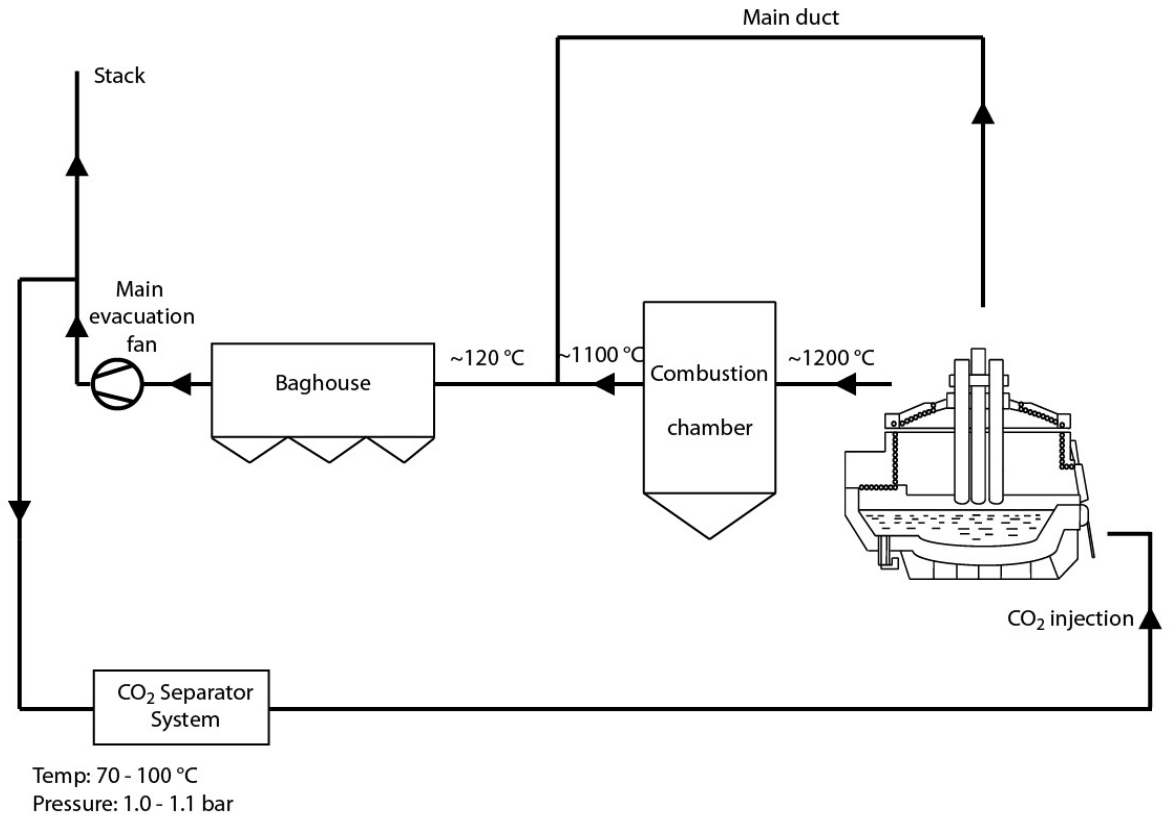

Fig. 3. The use of $\mathrm{CO}_{2}$ in the electric arc furnace

\section{RESEARCH METHOD}

Carbon dioxide is a gas that is produced during metallurgical processes as a result of carbon burning or so called afterburning of carbon monoxide. At the same time $\mathrm{CO}_{2}$ can react with carbon according to the so called Boudouard's reaction:

$\mathrm{CO}_{2}+\mathrm{C}=2 \mathrm{CO}$

It is an endothermic reaction in which $\Delta \mathrm{H}_{298}=-172,5 \mathrm{~kJ} / \mathrm{kg}$. Such a reaction apart from having other functions in metallurgical processes can also be used to decarburize the metal bath. This function is not used in practice. That is why the aim of this research was to verify the possibility of its application using carbon dissolved in the iron solution.

The research was conducted on the basis of the following assumptions:

- phosphorus content

below $300 \mathrm{ppm}$,

- carbon content

below $2 \%$,

- temperature

- basicity of slag approx. $1500{ }^{\circ} \mathrm{C}$,

- $\mathrm{CO}_{2}$ injection $1.2-1.4$, $10 \mathrm{dm}^{3} / \mathrm{min}$,

- duration of the injection 10-20 min.

Ten heats were conducted in a $20 \mathrm{~kg}$ induction furnace. In order to obtain the carbon content in molten metal bath ranging from $0.1 \%$ to approx. $2.0 \%$, the metal charge was 
made of pig iron $0-8 \mathrm{~kg} / 20 \mathrm{~kg}$ of the metal charge and low-alloy steel $(0.4 \%$ carbon and $0.9 \%$ chromium $)$. Lime $(0.5 \mathrm{~kg})$ and mill scale $(0.1 \mathrm{~kg})$ were also added to the charge. In the last heat was used $20 \mathrm{~kg}$ of pig iron.

After the charge had been heated, the temperature of the metal bath was measured. Depending on the type of the charge the temperature ranged from $1420-1559{ }^{\circ} \mathrm{C}$. Metal samples for chemical analysis were also collected.

The next technological operation consisted in injecting $\mathrm{CO}_{2}$ into the metal bath. The gas was blown into the metal bath using a steel pipe. The intensity of the blow amounted to $10 \mathrm{dm}^{3} / \mathrm{min}$. Depending on the temperature of the metal bath there was one continuous blow or there were several interrupted blows. The latter case accompanied by temperature measurements and sample collection made it possible to analyze the kinetics of the process.

\section{RESEARCH RESULTS}

The obtained results are shown in Figures 4-8. Figure 4 shows the influence of the initial amount of carbon in the metal bath on the kinetics of the decarburization process.

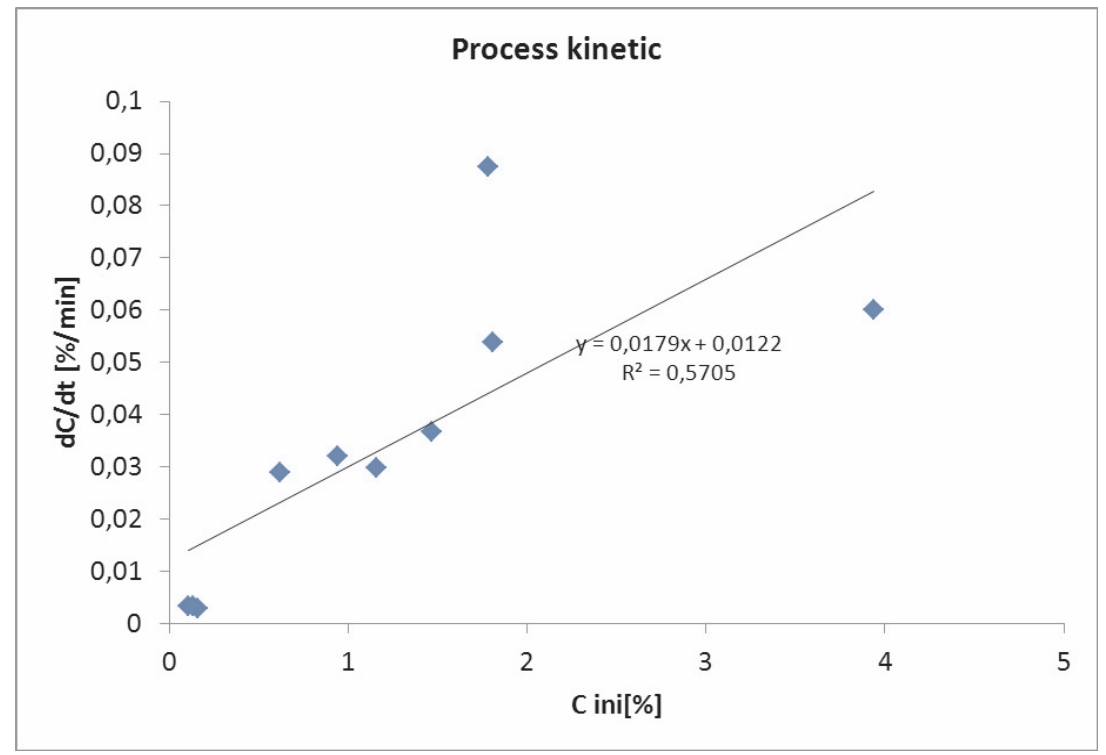

Fig. 4. The kinetics of the metal bath decarburization

If one analyzes the results in Figures 5 and 6, one can observe a severe decrease in carbon and silicon content in metal bath during the $\mathrm{CO}_{2}$ injection. In the case of higher initial amounts of carbon in the metal bath, the decrease is even more significant. Figure 6 shows the results of oxidation of silicon using $\mathrm{CO}_{2}$. It shows that the effectiveness of desiliconization metal increases with increasing silicon content in the metal bath. At low contents of silicon, less than $0.1 \%$, metal desiliconization was low. 


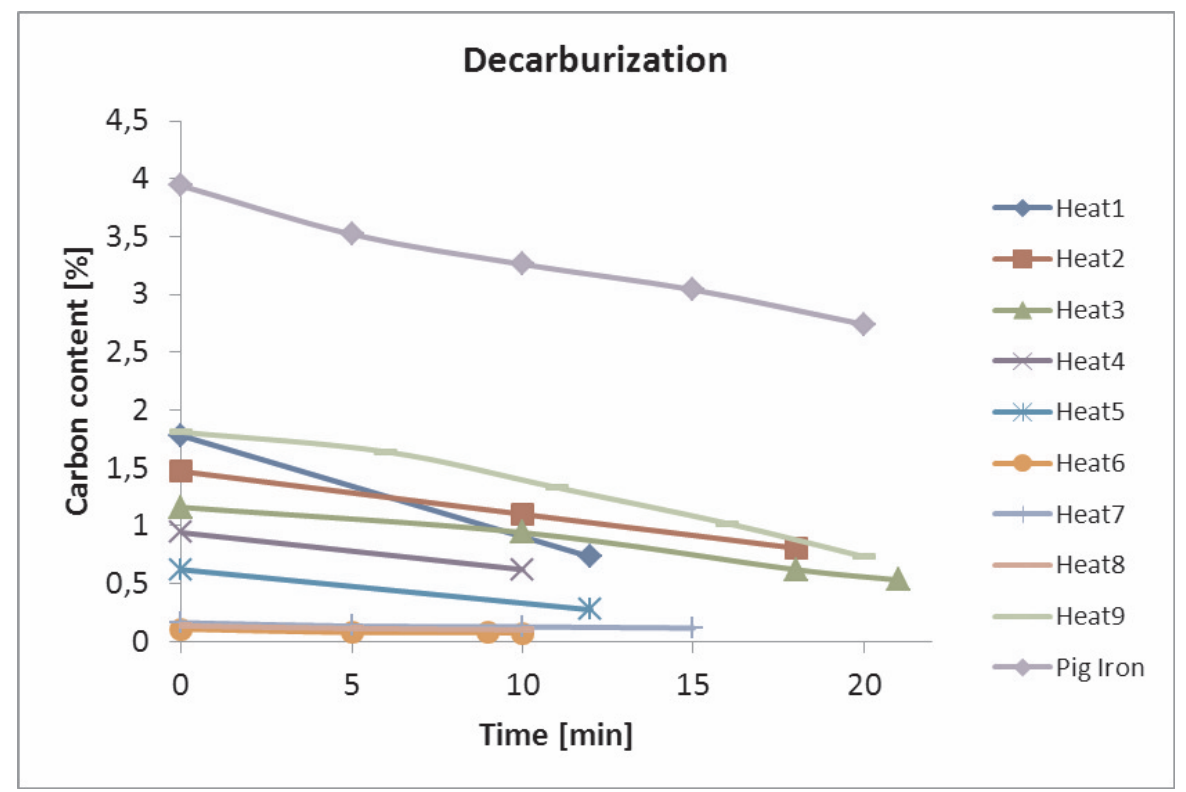

Fig. 5. The changes in carbon content in metal bath during the $\mathrm{CO}_{2}$ injection

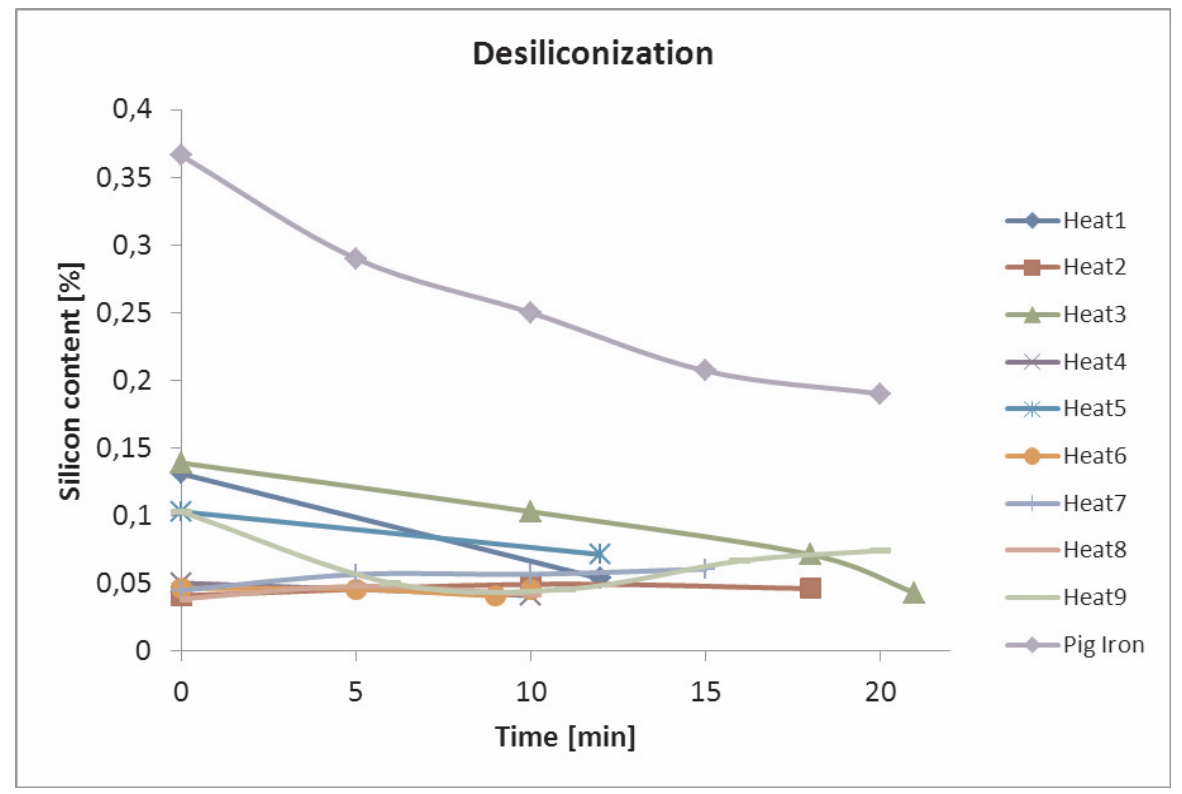

Fig. 6. The changes in silicon content in metal bath during the $\mathrm{CO}_{2}$ injection 


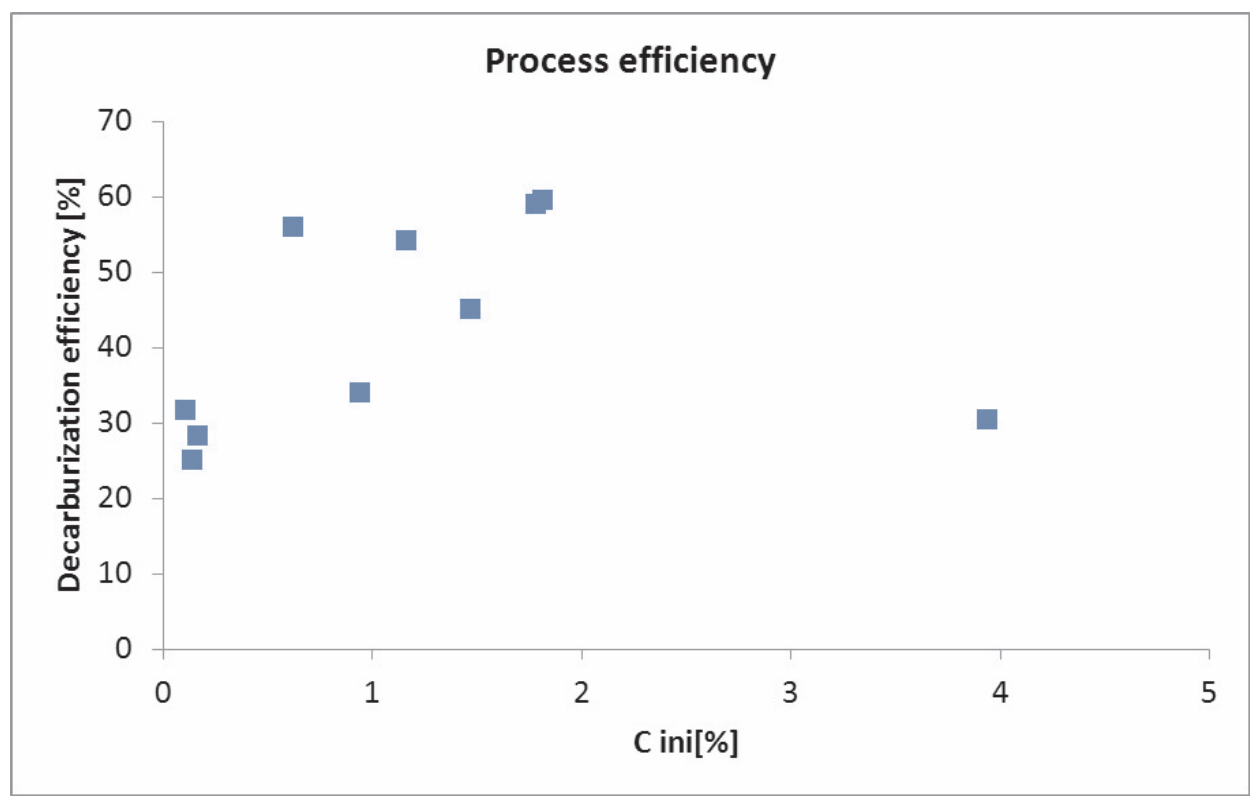

Fig. 7. The efficiency of the metal bath decarburization

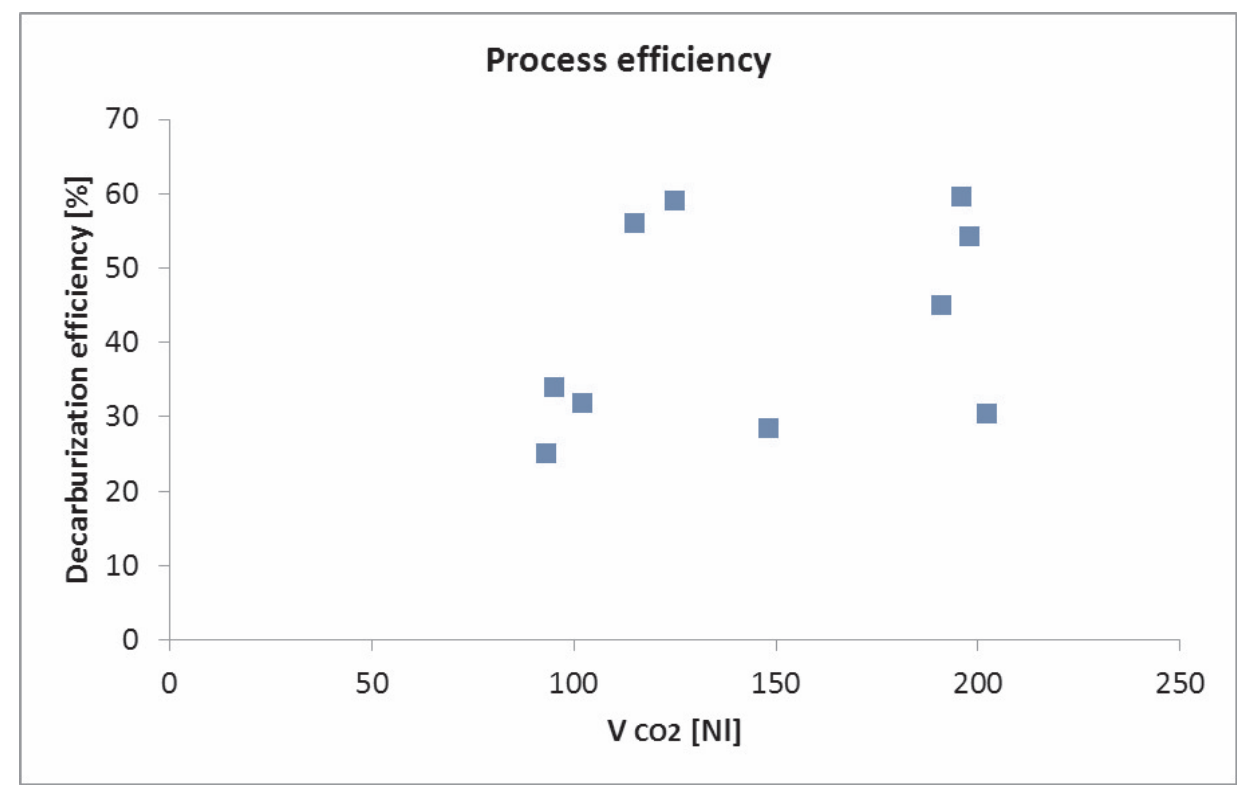

Fig. 8. The influence of the $\mathrm{CO}_{2}$ injection volume on the metal bath decarburization 
Higher carbon content causes the kinetics of the decarburization process to increase. It can be calculated as a quotient of the decrease in carbon content and time.

Figures 7 and 8 show the influence of the $\mathrm{CO}_{2}$ injection and initial content of carbon on the efficiency of decarburization. The efficiency of decarburization tends to increase when the $\mathrm{CO}_{2}$ content increases. The statistical correlation, however, seems to be irrelevant.

\section{SUMMARY}

The experiments conducted in laboratory conditions brought important results. These results will help to develop further the decarburization technology based on blowing $\mathrm{CO}_{2}$ into the metal bath in industrial conditions i.e. ferroalloys refining. The problem of global warming inspires researchers to look for "clean" technologies and new ways to use $\mathrm{CO}_{2}$ in industrial conditions. As part of the European ULCOS project 48 companies are cooperating in order to develop $\mathrm{CO}_{2}$ recycling technologies in metallurgical processes.

\section{Acknowledgements}

This work was carried out with financial support through statutory funds of AGH-UST No. 11.11.110.930.

\section{REFERENCES}

[1] Taguchi K., Ono-Nakazato H., Usui T., Marukawa K.: Desiliconization and decarburization behavior of molten Fe-C-Si(-S) alloy with $\mathrm{CO}_{2}$ and $\mathrm{O}_{2}$, Metall. Mater. Trans. B, 34B (2003), 861-867

[2] Lv M., Zhu R., Wei X., Wang H., Bi X.: Research on top and bottom blowing $\mathrm{CO}_{2}$ in converter steelmaking process, Steel Research Int., 83 (2012) 1, 11-15

Received

November 2012 